\title{
Synthesis of trifluoromethyl-substituted pyrazolo[4,3-c]pyridines - sequential versus multicomponent reaction approach
}

\author{
Barbara Palka ${ }^{1}$, Angela Di Capua ${ }^{1,2}$, Maurizio Anzini ${ }^{2}$, Gyté Vilkauskaité ${ }^{1,3}$, \\ Algirdas Šačkus ${ }^{3}$ and Wolfgang Holzer ${ }^{* 1}$
}

\section{Full Research Paper}

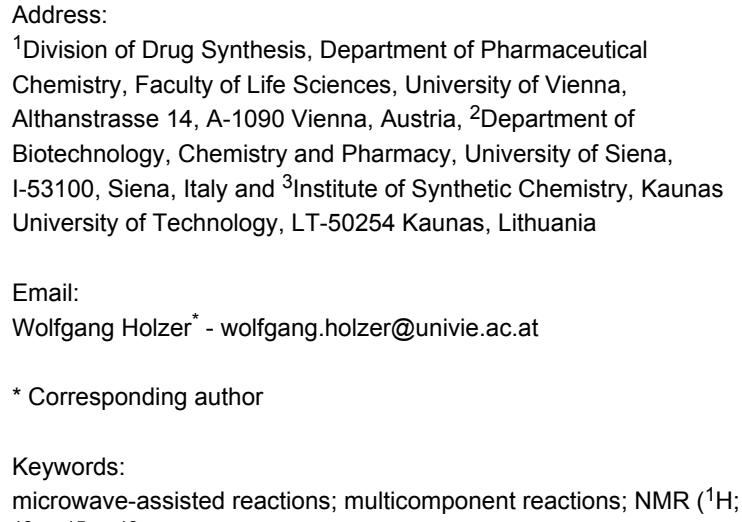

${ }^{1}$ Division of Drug Synthesis, Department of Pharmaceutical Chemistry, Faculty of Life Sciences, University of Vienna, Althanstrasse 14, A-1090 Vienna, Austria, ${ }^{2}$ Department of Biotechnology, Chemistry and Pharmacy, University of Siena, I-53100, Siena, Italy and ${ }^{3}$ Institute of Synthetic Chemistry, Kaunas University of Technology, LT-50254 Kaunas, Lithuania

Email:

Wolfgang Holzer ${ }^{*}$ - wolfgang.holzer@univie.ac.at

${ }^{*}$ Corresponding author

Keywords:

microwave-assisted reactions; multicomponent reactions; NMR $\left({ }^{1} \mathrm{H}\right.$;

${ }^{13} \mathrm{C} ;{ }^{15} \mathrm{~N} ;{ }^{19} \mathrm{~F}$ ); Sonogashira coupling; trifluoromethylpyrazoles
Beilstein J. Org. Chem. 2014, 10, 1759-1764. doi:10.3762/bjoc. 10.183

Received: 29 April 2014

Accepted: 11 July 2014

Published: 31 July 2014

This article is part of the Thematic Series "Multicomponent reactions II".

Guest Editor: T. J. J. Müller

(C) 2014 Palka et al; licensee Beilstein-Institut. License and terms: see end of document.

\begin{abstract}
A straightforward synthesis of 6-substituted 1-phenyl-3-trifluoromethyl-1H-pyrazolo[4,3-c]pyridines and the corresponding 5-oxides is presented. Hence, microwave-assisted treatment of 5-chloro-1-phenyl-3-trifluoromethylpyrazole-4-carbaldehyde with various terminal alkynes in the presence of tert-butylamine under Sonogashira-type cross-coupling conditions affords the former title compounds in a one-pot multicomponent procedure. Oximes derived from (intermediate) 5-alkynyl-1-phenyl-3-trifluoromethyl-1H-pyrazole-4-carbaldehydes were transformed into the corresponding $1 H$-pyrazolo[4,3-c]pyridine 5-oxides by silver triflate-catalyzed cyclization. Detailed NMR spectroscopic investigations $\left({ }^{1} \mathrm{H},{ }^{13} \mathrm{C},{ }^{15} \mathrm{~N}\right.$ and $\left.{ }^{19} \mathrm{~F}\right)$ were undertaken with all obtained products.
\end{abstract}

\section{Introduction}

Fluorine-containing compounds play an important role in medicinal and pharmaceutical chemistry as well as in agrochemistry [1-4]. A popular approach for the modulation of activity consists in the introduction of one or more fluorine atoms into the structure of a bioactive compound. This variation frequently leads to a higher metabolic stability and can modulate some physicochemical properties such as basicity or lipophilicity $[1,2]$. Moreover, incorporation of fluorine often results in an increase of the binding affinity of drug molecules to the target protein $[1,2]$. As a consequence, a considerable amount - 
approximately $20 \%$ - of all the pharmaceuticals being currently on the market contain at least one fluorine substituent, including important drug molecules in different pharmaceutical classes [5]. Keeping in mind the above facts, the synthesis of fluorinated heterocyclic compounds, which can act as building blocks for the construction of biologically active fluorine-containing molecules, is of eminent interest. In the field of pyrazoles, pyridines and condensed systems thereof trifluoromethyl-substituted congeners can be found as partial structures in several pharmacologically active compounds. In the pyridine series the HIV protease inhibitor Tipranavir (Aptivus ${ }^{\circledR}$ ) [6] may serve as an example, within the pyrazole-derived compounds the COX-2 inhibitor Celecoxib (Celebrex ${ }^{\circledR}$ ) is an important representative (Figure 1) [7].

In continuation of our program regarding the synthesis of fluoro- and trifluoromethyl-substituted pyrazoles and annulated pyrazoles $[8,9]$ we here present the synthesis of trifluoromethylsubstituted pyrazolo[4,3-c]pyridines. The latter heterocyclic system represents the core of several biologically active compounds, acting, for instance, as SSAO inhibitors [10], or inhibitors of different kinases (LRRK2 [11,12], TYK2 [13], JAK $[14,15])$.

\section{Results and Discussion Chemistry}

The construction of the pyrazolo[4,3-c]pyridine system can be mainly achieved through two different approaches. One strategy involves the annelation of a pyrazole ring onto an existing, suitable pyridine derivative [16]. Alternatively, the bicyclic system can be accessed by pyridine-ring formation with an accordant pyrazole precursor. Employing the latter approach we recently presented a novel method for the synthesis of the pyrazolo[4,3c]pyridine system by Sonogashira-type cross-coupling reaction of easily obtainable 5-chloro-1-phenyl-1 $H$-pyrazole-4-carbaldehydes with various alkynes and subsequent ring-closure reaction of the thus obtained 5-alkynyl-1H-pyrazole-4-carbaldehydes in the presence of tert-butylamine [17]. Furthermore, we showed that the oximes derived from the before mentioned 5-alkynylpyrazole-4-carbaldehydes can be transformed into the corresponding 1-phenylpyrazolo[4,3-c]pyridine 5-oxides [17].

For the synthesis of the title compounds a similar approach was envisaged. As starting material the commercially available 1-phenyl-3-trifluoromethyl-1H-pyrazol-5-ol (1) was employed which, after Vilsmaier formylation [18] and concomitant transformation of the hydroxy function into a chloro substituent by treatment with excessive $\mathrm{POCl}_{3}$, gave the chloroaldehyde 2 [19] (Scheme 1). Although Sonogashira-type cross-coupling reactions are preferably accomplished with iodo(hetero)arenes considering the general reactivity $\mathrm{I}>\mathrm{Br} / \mathrm{OTf}>>\mathrm{Cl}[20]-$ from related examples it was known that the chloro atom in 5-chloropyrazole-4-aldehydes is sufficiently activated to act as the leaving group in such kind of $\mathrm{C}-\mathrm{C}$ linkages [17]. Indeed, reaction of chloroaldehyde $\mathbf{2}$ with different alkynes $\mathbf{3 a}-\mathbf{c}$ under typical Sonogashira reaction conditions afforded the corresponding cross-coupling products $\mathbf{4 a - c}$ in good yields (Scheme 1). In some runs compounds of type 8 were determined as byproducts in differing yields, but mostly below $10 \%$, obviously resulting from addition of water to the triple bond of 4 under the reaction conditions (or during work-up) and subsequent tautomerization of the thus formed enoles into the corresponding ketones. The hydration of $\mathrm{C}-\mathrm{C}$ triple bonds under the influence of various catalytic systems, including also Pd-based catalysts, is a well-known reaction $[21,22]$. It should be emphasized that NMR investigations with compounds 8a,c unambiguously revealed the methylene group adjacent to the pyrazole nucleus and the carbonyl moiety attached to the substituent $\mathrm{R}$ originating from the employed alkyne.

In the next reaction step, alkynylaldehydes $\mathbf{4 a}, \mathbf{b}$ were cyclized into the target pyrazolo[4,3-c]pyridines $\mathbf{5 a}, \mathbf{b}$ in $71 \%$, resp. $52 \%$ yield by reaction with tert-butylamine under microwave assistance [17]. In view of the fact, that the two-step conversion $\mathbf{2} \rightarrow \mathbf{4 a}, \mathbf{b} \rightarrow \mathbf{5 a}, \mathbf{b}$ was characterized by only moderate overall yields (59\%, resp. 43\%) it was considered to merge these two steps into a one-pot multicomponent reaction. The latter type of reaction attracts increasing attention in organic chemistry due to

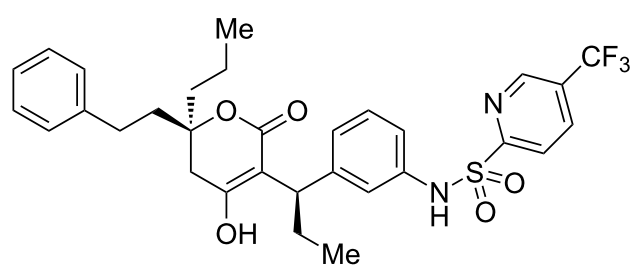

Tipranavir

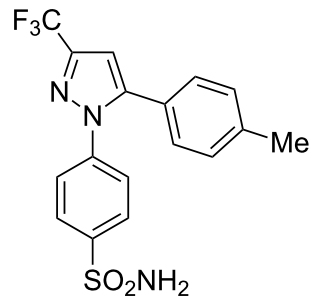

Celecoxib

Figure 1: Important drug molecules containing a trifluoromethylpyridine, respectively a trifluoromethylpyrazole moiety. 


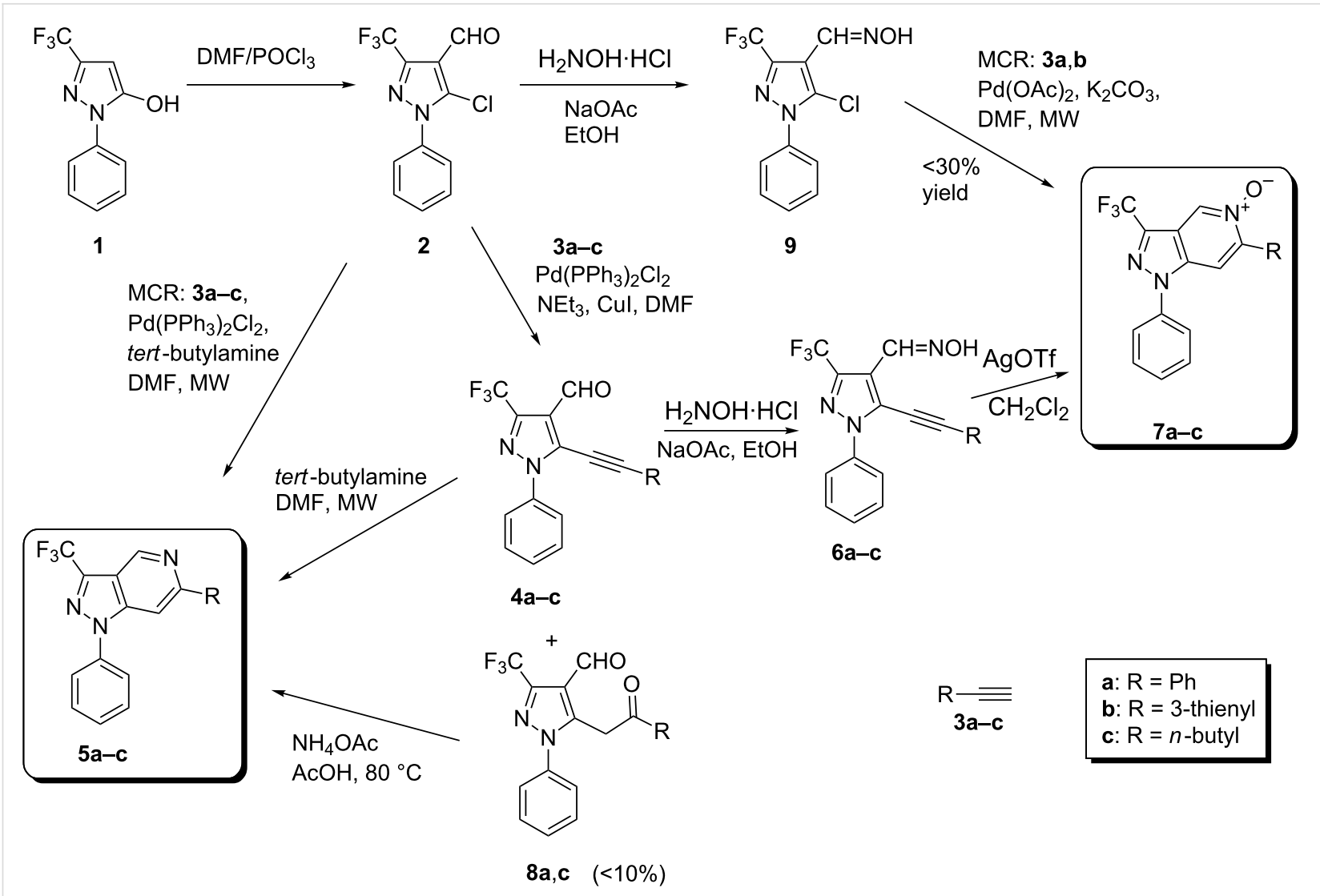

Scheme 1: Synthesis of the title compounds.

its preeminent synthetic efficiency, also in the construction of heterocyclic and condensed heterocyclic systems [23-27]. After testing different reaction conditions we found that microwave heating of the chloroaldehyde 2 with tert-butylamine in the presence of $6 \mathrm{~mol} \%$ of $\mathrm{Pd}\left(\mathrm{PPh}_{3}\right)_{2} \mathrm{Cl}_{2}$ afforded the desired pyrazolopyridines 5a-c in high (5a: 89\%, 5c: 92\%) respectively acceptable yields (5b: $51 \%$ ) in a single one-pot and copper-free reaction step (Scheme 1). It should be mentioned that compounds $\mathbf{5}$ are also accessible by heating of ketones $\mathbf{8}$ with ammonium acetate in acetic acid according to a procedure described in [28]. Following this way, $\mathbf{5 a}$ and $\mathbf{5 c}$ were obtained in $70 \%$ yield from the corresponding ketones $8 \mathbf{a}$ and $\mathbf{8 c}$. Although ketones $\mathbf{8}$ were only obtained as byproducts, the latter transformation allowed increasing the overall yield of compounds 5 through this 'bypass'.

In order to gain access to the corresponding $N$-oxides of type 7 , aldehydes $4 \mathbf{a}-\mathbf{c}$ were transformed into the corresponding oximes $\mathbf{6 a}-\mathbf{c}$ by reaction with hydroxylamine hydrochloride in ethanol in the presence of sodium acetate (Scheme 1). Subsequent treatment of the oximes with AgOTf in dichloromethane [29] finally afforded the corresponding pyrazolo[4,3-c]pyridine 5 -oxides $7 \mathbf{a}-\mathbf{c}$ by a regioselective 6 -endo-dig cyclisation [30] in high yields. Moreover, we tested an alternative approach to access compounds 7 through multicomponent reactions (MCR). Attempts to react chloroaldehyde $\mathbf{2}$ with hydroxylamine hydrochloride and an alkyne $\mathbf{3}$ in the presence of a suitable catalytic system were not successful. However, after conversion of $\mathbf{2}$ into the corresponding aldoxime $\mathbf{9}$ the latter could be transformed into the $N$-oxides $7 \mathbf{a}$ and $7 \mathbf{b}$ by reaction with alkynes 3a and 3b, respectively, employing $\mathrm{Pd}(\mathrm{OAc})_{2}$ as the catalyst and under microwave irradiation (Scheme 1). Although a number of different reaction conditions were tested, we were not able to increase the yields in excess of $30 \%$. Thus, with respect to the overall yields the successive approach $\mathbf{2} \rightarrow \mathbf{4} \rightarrow \mathbf{6} \rightarrow \mathbf{7}$ (overall yields: 6a: $62 \%, \mathbf{6 b}: 43 \%$ ) here is still advantageous compared to the multicomponent reaction following the path $\mathbf{2} \rightarrow \mathbf{9} \rightarrow \mathbf{7}$. Azine $N$-oxides of type $\mathbf{7}$ are estimated to be of particular interest due to the possibility of further functionalization adjacent to the nitrogen atom (position 4), for instance by palladium-catalyzed direct arylation reactions [31].

\section{NMR spectroscopic investigations}

In Supporting Information File 1 the NMR spectroscopic data of all compounds treated within this study are indicated. Full and unambiguous assignment of all ${ }^{1} \mathrm{H},{ }^{13} \mathrm{C},{ }^{15} \mathrm{~N}$ and ${ }^{19} \mathrm{~F}$ NMR 
resonances was achieved by combining standard NMR techniques [32], such as fully ${ }^{1} \mathrm{H}$-coupled ${ }^{13} \mathrm{C}$ NMR spectra, APT, HMQC, gs-HSQC, gs-HMBC, COSY, TOCSY, NOESY and NOE-difference spectroscopy.

In compounds 4-7 the trifluoromethyl group exhibits very consistent chemical shifts, ranging from $\delta(\mathrm{F})-60.8$ to $-61.9 \mathrm{ppm}$. The fluorine resonance is split into a doublet by a small coupling $(0.5-0.9 \mathrm{~Hz})$ due to a through-space (or possibly $5 J)$ interaction with spatially close protons $(4: \mathrm{CHO} ; 6$ : $\mathrm{CH}=\mathrm{N}$; 5 and 7: H-4). Reversely, the signals of the latter protons are split into a quartet (not always well resolved). The corresponding carbon resonance of $\mathrm{CF}_{3}$ is located between 120.2 and $121.2 \mathrm{ppm}$ with the relevant ${ }^{1} J(\mathrm{C}, \mathrm{F})$ coupling constants being approximately $270 \mathrm{~Hz}(269.6-270.6 \mathrm{~Hz})$. As well, the signal of C-3 is always split into a quartet $(J \sim 40 \mathrm{~Hz})$ due to the ${ }^{2} J\left(\mathrm{C}, \mathrm{F}_{3}\right)$ coupling.

As the ${ }^{15} \mathrm{~N}$ NMR chemical shifts were determined by ${ }^{15} \mathrm{~N},{ }^{1} \mathrm{H}$ HMBC experiments the resonance of (pyrazole) N-2 was not captured owing to the fact that this nitrogen atom lacks of sufficient couplings to protons, thus disabling the necessary coherence transfer $\left({ }^{19} \mathrm{~F},{ }^{15} \mathrm{~N}\right.$ HMBC spectra were not possible with the equipment at hand). For N-1, with pyrazole derivatives 4 and 6 remarkably larger ${ }^{15} \mathrm{~N}$ chemical shifts were detected ( -158.8 to $-160.2 \mathrm{ppm}$ ) compared to the corresponding signals for pyrazolopyridines 5 and 7 ( -182.2 to $-185.9 \mathrm{ppm})$. When switching from an azine to an azine oxide partial structure $(5 \rightarrow 7)$ the N-5 resonance exhibits an explicit upfield shift
(15.6-18.3 ppm), being typical for the changeover from pyridine to pyridine $N$-oxide [33].

NMR experiments also allowed the determination of the stereochemistry of oximes 6 : considering the size of ${ }^{1} J(\mathrm{~N}=\mathrm{C}-\mathrm{H})$ which is strongly dependent on lone-pair effects [34] as well as the comparison of chemical shifts with those of related, unambiguously assigned oximes [17] reveals $E$-configuration at the $\mathrm{C}=\mathrm{N}$ double bond.

With byproduct 8a the position of the carbonyl group unequivocally follows from the correlations between phenyl protons and the carbonyl C-atom and, reversely, from those between the methylene protons with pyrazole $\mathrm{C}-4$ and pyrazole $\mathrm{C}-5$ (determined by ${ }^{13} \mathrm{C},{ }^{1} \mathrm{H}$ HMBC).

In Figure 2 essential NMR data for the complete series of type $\mathbf{c}$ $(4 c, 5 c, 6 c, 7 c)$ are displayed, which easily enables to compare the notable chemical shifts and allows following the trends described above.

Full experimental details as well as spectral and microanalytical data of the obtained compounds are presented in Supporting Information File 1.

\section{Conclusion}

To sum up, the presented approach represents a simple method for the synthesis of 6-substituted 1-phenyl-3-trifluoromethyl$1 H$-pyrazolo[4,3-c]pyridines 5 and the analogous 5-oxides 7

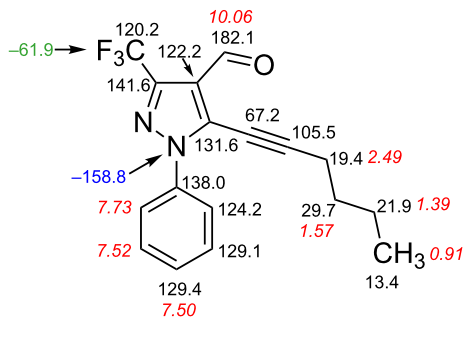

$4 \mathrm{c}\left(\mathrm{CDCl}_{3}\right)$

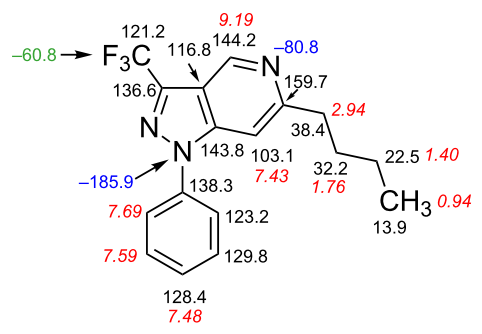

$5 \mathbf{c}\left(\mathrm{CDCl}_{3}\right)$

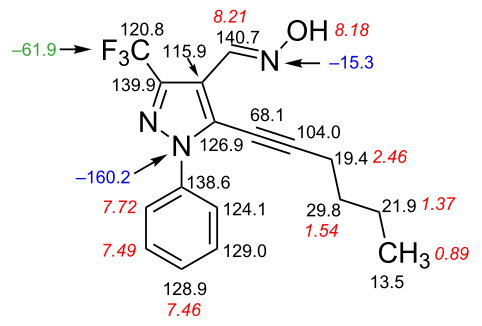

6c $\left(\mathrm{CDCl}_{3}\right)$

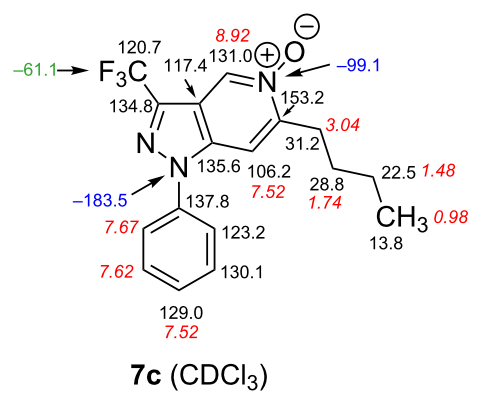

Figure 2: ${ }^{1} \mathrm{H}$ (in italics, red), ${ }^{13} \mathrm{C}$ (black), ${ }^{15} \mathrm{~N}$ (in blue) and ${ }^{19} \mathrm{~F} \mathrm{NMR}$ (green) chemical shifts of compounds $4 \mathrm{c}, 5 \mathrm{c}, 6 \mathbf{c}$ and $7 \mathrm{c}$ (in $\mathrm{CDCl}$ ). 
starting from commercially available 1-phenyl-3-trifluoromethyl-1H-pyrazol-5-ol (1). In the case of the former (5) the described multicomponent reaction approach is superior compared to the sequential one, whereas the step-by-step synthesis of $N$-oxides 7 is still characterized by higher overall yields. In addition, in-depth NMR studies with all synthesized compounds were performed, affording full and unambiguous assignment of ${ }^{1} \mathrm{H},{ }^{13} \mathrm{C},{ }^{15} \mathrm{~N}$ and ${ }^{19} \mathrm{~F}$ resonances and the designation of ascertained heteronuclear spin-coupling constants.

\section{Supporting Information}

\section{Supporting Information File 1}

Experimental details and characterization data.

[http://www.beilstein-journals.org/bjoc/content/ supplementary/1860-5397-10-183-S1.pdf]

\section{References}

1. Böhm, H.-J.; Banner, D.; Bendels, S.; Kansy, M.; Kuhn, B.; Müller, K.; Obst-Sander, U.; Stahl, M. ChemBioChem 2004, 5, 637-643. doi:10.1002/cbic.200301023

2. Hagmann, W. K. J. Med. Chem. 2008, 51, 4359-4369. doi:10.1021/jm800219f

3. Liu, P.; Sharon, A.; Chu, C. K. J. Fluorine Chem. 2008, 129, 743-766. doi:10.1016/j.jluchem.2008.06.007

4. Berkowitz, D. B.; Karukurichi, K. R.; de la Salud-Bea, R.; Nelson, D. L.; McCune, C. D. J. Fluorine Chem. 2008, 129, 731-742. doi:10.1016/j.jfluchem.2008.05.016

5. O'Hagan, D. J. Fluorine Chem. 2010, 131, 1071-1081. doi:10.1016/j.jluchem.2010.03.003

6. Poppe, S. M.; Slade, D. E.; Chong, K. T.; Hinshaw, R. R.; Pagano, P. J.; Markowitz, M.; Ho, D. D.; Mo, H.; Gorman, R. R., III; Dueweke, T. J.; Thaisrivongs, S.; Tarpley, W. G. Antimicrob. Agents Chemother. 1997, 41, 1058-1063.

7. Penning, T. D.; Talley, J. J.; Bertenshaw, S. R.; Carter, J. S.; Collins, P. W.; Docter, S.; Graneto, M. J.; Lee, L. F.; Malecha, J. W.; Miyashiro, J. M.; Rogers, R. S.; Rogier, D. J.; Yu, S. S.;

Anderson, G. D.; Burton, E. G.; Cogburn, J. N.; Gregory, S. A.; Koboldt, C. M.; Perkins, W. E.; Seibert, K.; Veenhuizen, A. W.; Zhang, Y. Y.; Isakson, P. C. J. Med. Chem. 1997, 40, 1347-1365. doi:10.1021/jm960803q

8. Bieringer, S.; Holzer, W. Heterocycles 2006, 68, 1825-1836. doi:10.3987/COM-05-10502

9. Holzer, W.; Ebner, A.; Schalle, K.; Batezila, G.; Eller, G. A. J. Fluorine Chem. 2010, 131, 1013-1024. doi:10.1016/j.jfluchem.2010.07.007

10. Savory, E.; Simpson, I. New compounds II. WO Pat. Appl. WO/2010/031791 A1, March 25, 2010.

11. Chan, B.; Estrada, A.; Sweeney, Z.; Mclver, E. G.; Mclver, S. Pyrazolopyridines as inhibitors of the kinase LRRK2. WO Pat. Appl. WO2011/141756 A1, Nov 17, 2011.

12. Chan, B.; Chen, H.; Estrada, A.; Shore, D.; Sweeney, Z.; Mclver, E. Pyrazolopyridines as inhibitors of the kinase LRRK2. WO Pat. Appl. WO2012/038743 A1, March 29, 2012.
13. Blench, T.; Goodacre, S.; Lai, Y.; Liang, Y.; MacLeod, C.; Magnuson, S.; Tsui, V.; Williams, K.; Zhang, B. Pyrazolopyridines and pyrazolopyridines and their use as TYK2 inhibitors. WO Pat. Appl. WO2012/066061 A1, May 24, 2012.

14. Oxenford, S.; Hobson, A.; Oliver, K.; Ratcliffe, A.; Ramsden, N. Pyrazolo[4,3-c]pyridine derivatives as JAK inhibitors. WO Pat. Appl. WO2013/017479 A1, Feb 7, 2013.

15. Oxenford, S.; Hobson, A.; Oliver, K.; Ratcliffe, A.; Ramsden, N. Preparation of pyrazolo[4,3-c]pyridine derivatives as JAK inhibitors. WO Pat. Appl. WO2013/017480 A1, Feb 7, 2013.

16. Lominac, W. J.; D’Angelo, M. L.; Smith, M. D.; Ollison, D. A.; Hanna, J. M., Jr. Tetrahedron Lett. 2012, 53, 906-909. doi:10.1016/j.tetlet.2011.12.055

17. Vilkauskaité, G.; Šačkus, A.; Holzer, W. Eur. J. Org. Chem. 2011, 5123-5133. doi:10.1002/ejoc.201100626

18. Meth-Cohn, O.; Stanforth, S. P. The Vilsmeier-Haack Reaction. In Comprehensive Organic Synthesis; Trost, B. M.; Fleming, I., Eds.; Pergamon: Oxford, 1991; pp 777-794. doi:10.1016/B978-0-08-052349-1.00049-4

19. Gilbert, A. M.; Bursavich, M. G.; Lombardi, S.; Georgiadis, K. E.; Reifenberg, E.; Flannery, C. R.; Morris, E. A. Bioorg. Med. Chem. Lett. 2007, 17, 1189-1192. doi:10.1016/j.bmcl.2006.12.020

20. Chinchilla, R.; Nájera, C. Chem. Rev. 2007, 107, 874-922. doi:10.1021/cr050992x

21. Hintermann, L.; Labonne, A. Synthesis 2007, 1121-1150. doi:10.1055/s-2007-966002

22. Li, X.; Hu, G.; Luo, P.; Tang, G.; Gao, Y.; Xu, P.; Zhao, Y. Adv. Synth. Catal. 2012, 354, 2427-2432. doi:10.1002/adsc. 201200420

23. Zhu, J.; Bienaymé, H., Eds. Multicomponent Reactions, 1st ed.; Wiley-VCH: Weinheim, 2005. doi:10.1002/3527605118

24. Dömling, A.; Ugi, I. Angew. Chem., Int. Ed. 2000, 39, 3168-3210. doi:10.1002/1521-3773(20000915)39:18<3168::AID-ANIE3168>3.0.CO ;2-U

25. D'Souza, D. M.; Müller, T. J. J. Chem. Soc. Rev. 2007, 36, 1095-1108. doi:10.1039/b608235c

26. Müller, T. J. J. Top. Heterocycl. Chem. 2010, 25, 25-94. doi:10.1007/7081_2010_43

27. Müller, T. J. J. Synthesis 2012, 159-174. doi:10.1055/s-0031-1289636

28. Deady, L. W.; Smith, C. L. Aust. J. Chem. 2003, 56, 1219-1224. doi:10.1071/CH03136

29. Yeom, H.-S.; Kim, S.; Shin, S. Synlett 2008, 924-928. doi:10.1055/s-2008-1042936

30. Baldwin, J. E.; Thomas, R. C.; Kruse, L. I.; Silberman, L. J. Org. Chem. 1977, 42, 3846-3852. doi:10.1021/jo00444a011

31. Campeau, L.-C.; Stuart, D. R.; Leclerc, J.-P.; Bertrand-Laperle, M.; Villemure, E.; Sun, H.-Y.; Lasserre, S.; Guimond, N.; Lecavallier, M.; Fagnou, K. J. Am. Chem. Soc. 2009, 131, 3291-3306. doi:10.1021/ja808332k

32. Braun, S.; Kalinowski, H.-O.; Berger, S. 150 and More Basic NMR Experiments: A Practical Course - Second Expanded Edition; Wiley-VCH: Weinheim, Germany, 1998.

33. Berger, S.; Braun, S.; Kalinowski, H.-O. 15N-NMR-Spektroskopie; NMR-Spektroskopie von Nichtmetallen, Vol. 2; Thieme: Stuttgart, New York, 1992; pp 42-43.

34. Gil, V. M. S.; von Philipsborn, W. Magn. Reson. Chem. 1989, 27, 409-430. doi:10.1002/mrc.1260270502 


\section{License and Terms}

This is an Open Access article under the terms of the Creative Commons Attribution License

(http://creativecommons.org/licenses/by/2.0), which permits unrestricted use, distribution, and reproduction in any medium, provided the original work is properly cited.

The license is subject to the Beilstein Journal of Organic Chemistry terms and conditions:

(http://www.beilstein-journals.org/bjoc)

The definitive version of this article is the electronic one which can be found at:

doi:10.3762/bjoc. 10.183 